\title{
The Pursuit of Empowerment through Social Media: Structural Social Capital Dynamics in CSR-Blogging
}

\author{
Christian Fieseler • Matthes Fleck
}

Received: 1 July 2012/Accepted: 16 July 2013/Published online: 20 November 2013

(C) Springer Science+Business Media Dordrecht 2013

\begin{abstract}
With the emergence of participative social media, the ways in which stakeholders may interact with companies are changing. Social media and Web 2.0 technologies change gatekeeping mechanisms and the distribution of information. In consequence, organizations must realize that they are structurally embedded in online networks of interconnected and equitable actors. In this paper, we analyze how this change in today's information and communication technologies may affect Corporate Social Responsibility (CSR) action. We utilize social network analysis to investigate the CSR blogs of three IT firms: Google, Hewlett-Packard, and Intel. The analysis reveals that their Internet-enabled social networks exhibit patterns of power law distribution and an uneven distribution of structural social capital among the actors involved, especially on the corporate side, which fails to fully engage with the network. We conclude by indicating the research implications of shifting social capital dynamics and by deriving implications for management and practice.
\end{abstract}

Keywords Online communication - Social media · Social network analysis - Structural social capital . Web 2.0

\section{Fieseler $(\square)$}

Institute for Media and Communications Management, University of St. Gallen, Blumenbergplatz 9, 9000 St. Gallen, Switzerland

e-mail: christian.fieseler@unisg.ch

\section{Fleck}

Institute for Communication and Marketing, Lucerne School of Business, Zentralstrasse 9, P.O. Box 2940, 6002 Lucerne,

Switzerland

e-mail: matthes.fleck@hslu.ch

\section{Introduction: New Media, New Rules?}

Social media are changing the classic dynamics of stakeholder relations. Virtual cooperation, networking, and cocreation have literally empowered previously underrepresented stakeholders (Tapscott and Williams 2006). Based on more efficient means of communication such as weblogs (Blood 2004), social networks (Boyd and Ellison 2007), social bookmarking sites (Golder and Huberman 2006), wikis (Spinellis and Louridas 2008), and virtual worlds (Louie 2007), it has become much easier for dispersed individuals with seemingly marginal concerns to connect and collectively promote issues (Towner and Dulio 2011; Wattal et al. 2010). Social media may thus give a voice to an even wider range of social and environmental concerns. However, there is also evidence suggesting that there is inequality in social media usage (Hargittai 2010; Hargittai and Walejko 2008). In this new media environment, the breadth and frequency of participation and discussion may lead to the emergence of a system that may be dominated by either more traditional patterns of interplay (or non-interplay) among elite contributors such as corporate and activist organizations or the increasing participation of non-professional, single-issue, or discussionoriented stakeholders.

In this paper, we wish to explore the forms of this interplay that can arise between nonprofessional and professional actors in the online disclosure and discussion of ethical, social, and environmental performance. Although there is a broad research tradition with regard to the context of stakeholder theory, non-institutionalized exchange relationships between organizations and a networked group of readers on the Web are less common. Research on citizens' online participation has made significant strides in analyzing both antecedents and outcomes of social media 
use. Some have been distinctly pessimistic in their assessment of these outcomes: Bennett and Iyengar (2008) warn that new media will lead to a fragmentation of audiences that will make the identification and timely engagement of interest groups increasingly more difficult. The coproduction and corresponding exponential increase in available information may not only devalue traditional channels of communication-mass media, most notablybut also lead to increasing partisan selectivity in interest group communication. Similarly, Dahlgren (2005) identifies a challenge in the dispersion of organizational forms of advocacy groups as new technologies create communities that are increasingly loose, horizontal, and fluid. Other researchers have argued that the simplicity of finding likeminded friends online may lead to a fragmentation of the public audience, increasing homogenization within communities and increasing polarization and confrontation among them (Scheufele et al. 2006; Woodly 2007; Nie et al. 2010). Paradoxically, increasing polarization may also lead to an increase in participation, as more ideological or polarized citizens may feel a stronger need to organize and affect public outcomes (Lawrence et al. 2010). To further understand how organizations engage in social media on these issues, this paper utilizes social network analysis to reveal the current engagement effects that organizations achieve by disclosing CSR via social media channels.

We use the example of three pioneering sustainability blogs written for the IT industry by Google, HewlettPackard, and Intel and analyze them according to Chen's (2009) conceptual outline for the investigation of corporate responsibilities in Internet-enabled social networks. In his framework, Chen (2009) proposes empirical investigation into the positions and responsibilities of firms within the informal networks that are created by social media user engagement. It is these informal relationships between organizations and the various users of social media that are of interest in this paper. The position and activity of an actor has an influence on the flow of information in the network and defines its potential to influence conversations. Differences among individuals grounded in their network position are often discussed in the literature using the term (structural) social capital (Burt 2000).

Several questions will guide the analysis. First, we will inquire regarding the connections of corporate blogs discussing CSR topics (in our case, the social and green use of information technology) to other blogs and determine who is behind these blogs and what they primarily discuss. By doing so, we will reveal the structural embeddedness, i.e., the social structure surrounding the blogs investigated. Second, we will analyze in what ways their structural embeddedness in online social networks affect the distribution of information and the potential to reach others in the network and their social capital (cf. Burt 2000; Adler and Kwon 2000). Third, we will discuss what strategic implications, if any, can be drawn from their structural embeddedness.

Our approach will be as follows: structural embeddedness will be analyzed at the individual level of each blog (by means of network centrality), and network structure will be measured (by means of network density-the number of relations existing among actors in relation to the maximum number of relations possible in a network). Information on density allows conclusions to be drawn regarding the similarity of actors. The more relations these actors share, the more likely it is that these actors share ideas, beliefs, and norms (Burt 2005). Finally, we will differentiate possible subgroups within these networks (by means of ego-networks). In this way, we can reveal each actor's level of activity and potential access to information. This approach is the empirical equivalent of Chen's (2009) general proposal to discuss networked properties and their effect on corporate responsibility at the individual, network, and group levels. Building on this analysis, the discussion of the implications of these network structures will be organized using an adaptation of Lin's (1999) conceptualization of social capital. This discussion will be divided into three parts: preconditions (which will explore social software's impact on surrounding social structures and individual positions within the social structure), capitalization (which will explore how social software alters the subsequent access, use and mobilization of social networks), and the effects of social networks (which will explore possible returns given the existing network structure).

Thus, overall, we will discuss whether and how this particular engagement practice, namely, how organizations communicate CSR on social media platforms, changes the way in which organizations engage their stakeholders. Given the virtual absence of prior research in this area, we focus on an exploratory rather than a hypothesis-driven approach to develop a picture of current practice. Adopting a social, Internet-enabled network approach to CSR and Web 2.0 has analytical appeal because the interplay among businesses, social relationships, and networks within which firms are entwined overlaps with the thinking behind CSR, including issues such as transparency, honesty, cooperation, trust, community investment, organizational citizenship, and goodwill (Spence et al. 2003). CSR might be viewed from this perspective as a process of investment in social networks, or more broadly speaking, in structural social capital, in which ostensibly altruistic behaviors may actually achieve long-term payback in terms of enhancing the firm's reputation, creating a favorable climate of opinion regarding the firm and possibly attracting reciprocal favors, as will be explained next. 


\section{Theoretical Foundations: Social Networks and the Internet}

Social media have been powerful in connecting likeminded individuals, providing an infrastructure for communities and supporting their coordination (Wilson and Peterson 2002). Analyses of social media are often framed within a context of social capital formation because applications such as social network websites support discursive communication (Boyd and Ellison 2007; Pasek et al. 2009; Etter and Fieseler 2010) and allow pursuers of political and social interests to join conversations (Woodly 2007; Gil de Zuniga et al. 2010) and bond with peers sharing similar views (Steinfield et al. 2008). In fact, the mere structure of social media has been considered an antecedent to social capital creation and maintenance (cf. Ellison et al. 2007; Adler and Kwon 2000), suggesting that online networks foster mutual enrichment through conversation, exchange, and participation (Zhang et al. 2009). In addition, social media are believed to reduce transaction and coordination costs, making it easier for like-minded citizens to come together around foci of interest (Nie et al. 2010; Wattal et al. 2010).

Likewise, by engaging in dialog with stakeholders regarding CSR issues, organizations aim to create social capital. Social capital is a result of social structure, individual agency, and personal literacy, either providing or denying opportunities for individual and organizational actors. Social capital has been investigated extensively in organizational settings, where it has been linked to benefits such as the obtainment of information, influence and solidarity within groups (Dore 1983; Ferrary 2003; Sandefur and Laumann 1998; Tsai and Ghoshal 1998). The benefits derived from the possession of social capital allow individuals and organizations to achieve ends that would not otherwise be possible or would incur additional costs (Adler and Kwon 2002; Field 2003; Woolcock 1998).

Social capital is linked to other types of capital such as economic, cultural, and symbolic capital (Bourdieu 1986). For McBain (2005, p. 25), social capital involves resources such as psychological states and behavioral expectations that are embedded within and available through a network of relationships. For Putnam (2000, p. 52), social capital is the connections among individuals' social networks and the norms of reciprocity and trustworthiness that arise from them. According to Nahapiet and Ghosal (1998, p. 243), social capital is the sum of the actual and potential resources embedded within, available through, and derived from the network of relationships possessed by an individual or social unit. In combining the different perspectives on this metaphor, they claim that social capital has structural, relational, and cognitive dimensions.
Certain network positions allow actors to exploit their positions better than others (Burt 1997). This structural dimension describes the totality of the impersonal configurations of linkages between actors (Nahapiet and Ghoshal 1998; Wasserman and Faust 1994; Scott 2000). At the heart of this structural dimension of social capital is the presence or absence of network ties between actors associated with the possession of direct and indirect ties, as well as the configuration of the focal actor's network (Scott 2000; Wasserman and Faust 1994). This structural embeddedness of ties, such as the (metaphorical) bridges between otherwise isolated groups of actors, which are commonly called structural holes, enables certain actors within the networking structure to obtain more advantages through brokerage. From a structural perspective, social capital is based on the network mechanisms of brokerage and closure (Burt 1982, 1999, 2000, 2005). In this structural view, actors can profit from either information flow within groups (closure) or from the exploitation of information flow between groups (brokerage). Further elaborating on the antecedents, Flap and Graaf (1988) emphasized that social capital is a combination of (a) network size, (b) the strength of relations in a network, and (c) resources acquired by the network participants.

Although social capital takes many forms, each of these forms has two characteristics in common: (1) they constitute some aspect of the social structure, and (2) they facilitate the actions of individuals or organizations within the structure (Coleman 1990). Social capital arises either from personal or impersonal sources of cooperation. Sanctions by an external authority, social norms, and values are considered impersonal sources (Granovetter 1985; Dore 1983). In contrast, personal sources are the result of cooperation with other actors that can provide benefits for the focal actor (Parkhe 1993; Heide and Miner 1992; Hill 1990). Although impersonal sources of cooperation are primarily given for individual actors and can only be altered indirectly, if at all, personal sources are not and can be influenced, as they arise in specific and personalized interactions.

Thus, self-interested and otherwise purposive actors may strategically enter into certain types of relationships (Bourdieu 1977; Coleman 1990; Field 2003; Portes 1998; Sandefur and Laumann 1998). Social capital results from an investment in social relations by individuals or organizations through which they gain access to embedded resources in order to enhance expected returns of instrumental or expressive action (Lin 1999). Overall, scholars of social capital share the belief that interaction among actors of a network creates and maintains social assets. Social capital describes individual and social structures that are accessible for research at the micro- and macro-levels of analysis. In other words, social capital is a metaphor that 
can describe the individual performance of an actor within a network, the performance of groups or certain clusters within networks or the overall performance of a network.

Earlier studies in the field of social capital and the Internet focused on the question of whether the Internet is decreasing or increasing social capital. Wellman et al. (2001) noted that the Internet might lead to the creation of larger social networks with a larger number of weak ties. They also emphasized that activities on the web can be divided into social (such as e-mail) and non-social activities (such as surfing or reading). The work of Kavanaugh and Patterson (2001) indicated that the Internet facilitates capitalization on existing social networks, while also introducing new participants to the dialog. Kavanaugh et al. (2005) subsequently illustrated the importance of said weak relations on the Internet, which act as bridges between individuals. Research by Hampton (2003) regarding the effects of ICT on a residential community also produced evidence that the Internet facilitates the maintenance of such weak ties. Beaudion and Tao (2007) indicated the possible effects of Internet-mediated communication on the social capital of cancer patients. Adding to these observations regarding weak ties and social capital, research by Mathwick et al. (2007) indicated that social capital in virtual communities is based on voluntarism, reciprocity and social trust. Such findings emphasize the potential importance of the Internet with regard to social capital. However, many of these studies discuss the Internet in light of only its first stage of evolution.

In what can be characterized as the second stage of the evolution of the Internet, the term Web 2.0 is used to describe the various developing forms of web-based cooperation and data exchange, as well as changing social dynamics. In its essence, this term describes the evolution from a read-only Web to a read-write Web (Warr 2008). In brief, Web 2.0 allows for the creation, modification and distribution of almost every imaginable type of digital content and leads to new social and economic phenomena. Social media and Web 2.0 are often used interchangeably (Berthon et al. 2012). Social media can be understood as an umbrella term subsuming the various channels that allow users to connect, whereas Web 2.0 is the sum of underlying concepts and technologies used by social media (Pitt 2012). This new Internet has the potential to fundamentally change organizations and the ways in which individuals cooperate and communicate. Peer production, crowd-sourcing and cocreation entail a shift in organizational thinking (Prahalad and Ramaswamy 2004). This shift is one from the linking of information to the linking of people.

Many of the dynamics of social media have led to visionary prophecies regarding user democracy and other forms of increased power among Internet users. Lately, enthusiasm has declined, and the need for more substantial analysis and conceptualization has become evident. Rushkoff (2011) summarized this critique with regard to the changing role of users and explains potential defense strategies. A societal view on Web 2.0 is employed by Morozov (2011), who notes that political engagement via blogs and Facebook will not necessarily end in social change. We can maintain that in essence, Web 2.0 platforms are intended to be dialogic. For instance, comments accompanying the original post are often at least as compelling to many readers as the post itself. In addition, many social audiences represent coherent groups of experts or individuals.

However, the question remains whether the purported equalizing effects of social media also can be applied in practice. In this context, from a structural perspective, this study explores the various interactions within the blogosphere of three corporate sustainability blogs in the IT industry. Expanding upon this idea and striving for a deeper understanding of the embeddedness of corporate sustainability blogs, we concentrate on exploring the CSR blogosphere that formed (at the time of writing) around the three pioneering CSR blogs.

\section{Method and Data collection}

For clarity in exposition, in the following analysis, we consider only the structural dimension of social capital. We recognize, however, that both the relational and cognitive dimensions are likely to be inter-related with both the structural configurations of the networks as well as the outcomes that an organization achieves using these networks. The analysis of structural dimensions offers two advantages. First, data can be collected automatically, as it is transparent and reproducible through the use of public crawler applications. Second, the structural dimension establishes the playing field for each actor and defines his role and influence in the flow of information.

With regard to the examination of online CSR engagement that is still in an early stage, we decided to highlight structural social capital with case studies of three CSR blogs and the surrounding network structures. These blogs are those of semiconductor chipmaker Intel (http://blogs. intel.com/csr/), search engine provider Google (http://blog. google.org/), and computer systems producer HewlettPackard (at the time: http://www.communities.hp.com/ online/blogs/csremea/default.aspx). These three blogs where chosen for their pioneering treatment of CSR topics; all three also share a common industry context, which allows for better comparison. In addition to the production facilities of Intel and HP, all three companies either exert a high demand for power consumption or produce goods with high power consumption (e.g., at the time of our analysis, Google's operations continuously drew 260 
million watts - approximately a quarter of the output of a nuclear power plant).

For our study, we use methods derived from social network analysis that describe social environments as relationship patterns among interacting units (Scott 2000; Wasserman and Faust 1994). Blog data were primarily chosen for their transparency (as everybody can gather these data) and their ability to render social structure and the social choices of their authors visible through hyperlinks (Park 2003). Our analysis began with the CSR blogs of Intel, Google, and Hewlett-Packard and ended with a two-step ego-network. Ego-networks represent the surrounding environment of an actor or a set of chosen actors, in our case, comprising other websites that link to or comment on the focal blogs.

For each focal actor, connected nodes were identified and then added to the network. For the two-step ego-networks, this procedure was reapplied to all newly identified actors, which means that every node in the network is, at most, two steps away from the focal actor (Wasserman and Faust 1994; Scott 2000; Hanneman and Riddle 2005). To ensure transparency during the data collection phase, we relied on Issuecrawler (see www.issuecrawler.org), an application that facilitates the collection of data from online networks for scientific purposes. Among other uses, Bruns (2007) has used the Issuecrawler application to map blogs. On a cautionary note, we would like to stress that the issuecrawler application does not crawl large bloghosters (e.g., blogspot, WordPress) or large search engines. Therefore, the data collected focus on (potentially) larger and thereby more relevant sites, as sites that are primarily programmed to influence search engines or to avoid splogs are excluded (see Kolari et al. 2006). What is lost, however, is the opportunity to identify microstructures consisting of non-institutionalized individuals, as shown by Fieseler et al. (2010). Nevertheless, it should be noted that each node identified is connected to multiple private and smaller blogs that are not shown in the analysis but can further multiply the effects of the focal blogs. The data were collected from the beginning of December 2009 until the end of that year's UN Climate Change Conference on December 15th. The time period was chosen because public attention was devoted to issues such as carbon emissions and climate change, which are also covered by the blogs investigated.

\section{Findings: The Structural Embeddedness of CSR Blogs}

\section{Individual Actors}

Our analysis of the three sustainability blogs begins at the level of the individual actors. At the individual actor level, we are interested in how the corporations' blogs linked to and were linked to by the other websites. Examining our network, the analysis yielded a total of 98 blogs that were connected to at least one of the focal CSR Blogs of Intel, Hewlett-Packard and Google. The combined network of all investigated blogs (Fig. 1) and the three ego-networks of the focal blogs are shown in Figs. 2, 3, and 4. In these visualizations, initial nodes are visualized with triangles and all other nodes are visualized as squares. Furthermore, the size of the nodes represents the number of incoming links. Incoming links, or Indegree-Centrality (Freeman 1979), measures the popularity and prominence of a network (Knoke and Burt 1983). Relating these measures back to the discussion on the online communication of corporate responsibilities, Chen summarized that central actors have a greater effect on other actors in the network (Chen 2009: 533). For example, empirically, the actor's effect on other actors is the actor's influence on information dissemination, or to be more precise, the likeliness of being read, cited, commented on, linked to and/or found by others. The visualization reveals that a number of blogs have a similar or even higher Indegree than the focal actors. This result suggests that even in the nearest network neighborhood, there are actors more powerful than the initial, corporate CSR blogs.

In Fig. 2, the network that forms around Intel's CSR blog at the time of the UN Climate Change Conference is visualized. The node sizes are depicted according to their Indegree; i.e., those blogs that do not belong to the Intel Corporation are marked as squares, whose size is dependent on the number of actors in the network that link to the website. Intel, the focal actor, is not among the most powerful in discussing the topics that are the basis of their CSR efforts-the visualization reveals that Intel's CSR blog is of relatively marginal influence in its close network vicinity.

In Fig. 3, the network of Hewlett-Packard's CSR blog at the time is depicted. Again, the nodes, i.e., the websites, are visualized in relation to the number of incoming links. As with the overall network and Intel's CSR blog, the visualization again reveals that other actors are more powerful in the network than the focal actor, the Hewlett-Packard Corporation.

Finally, in Fig. 4, the neighborhood of Google's CSR blog is depicted. In this case, at the time of the UN Climate Change Conference, Google's CSR activities were so poorly connected to other actors on the Internet that we had to visualize the two-step neighborhood, i.e., websites linking to websites that link to Google. Considering the low number of incoming links, in structural terms, the Google blog commands only marginal importance, and therefore has little to no chance to influence or inform other actors in the network. 


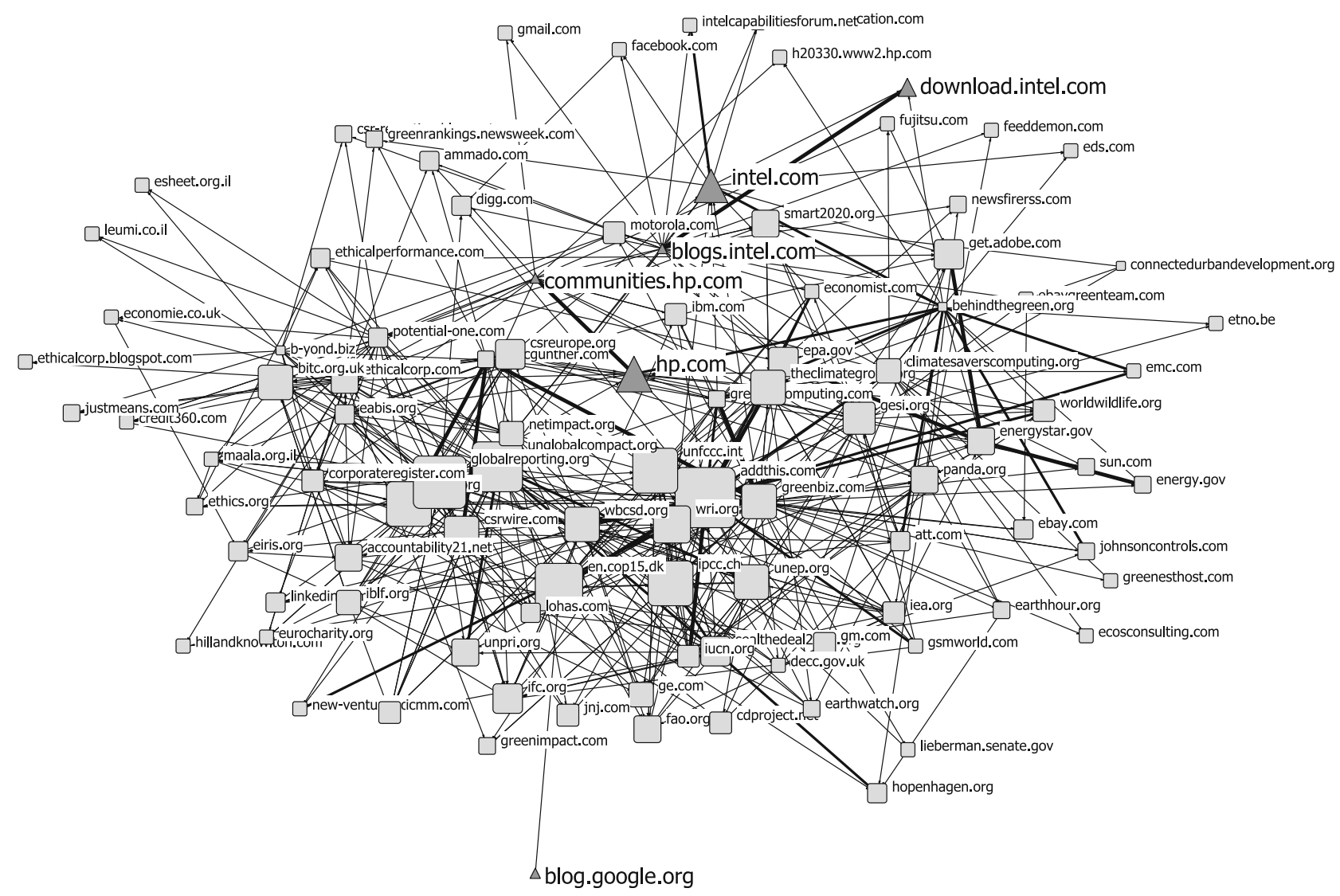

Fig. 1 Overall network (visualized with UCInet 6.0: Borgatti et al. 2002)

The interpretation of network structures can sometimes be quite vague. However, in this case, the three visualized structures of the ego networks (see Figs. 2, 3, and 4) of the corporate blogs investigated exhibit similar patterns. In each case, the focal blogs are not among the most prominent actors of the network. This pattern is even more impressive when one considers that ego networks tend to overstate the relationships of the focal actor.

In Fig. 5, the InDegree and OutDegree distributions of the initial blogs and the blogs they are surrounded by are shown. For the incoming as well as the outgoing links, a minority of actors is responsible for a majority of the links. Thus, information can travel quickly and efficiently in this network as long as the most prominent actors are involved (This pattern is analogous to the hub and spoke system of airlines, in which major cities are directly connected to each other, whereas smaller cities can only be accessed by connecting flights via major cities). Along the same lines, the patterns observed in the data indicate that in many cases, it might be desirable for the audience to talk directly to a CSR expert or an activist but not necessarily engage with firms on matters of green and social IT. If at all, they are "accessed" indirectly via aggregators such as influential blogs that summarize a number of ongoing discussions.
In effect, the message that the corporations intend to relate must pass through the filter of third parties.

The preliminary visual analysis indicates that some blogs hold more influence, i.e., centrality, than the initial nodes. We then proceeded to investigate which nodes were among those that were central, if not the corporations. Table 1 indicates the top 30 blogs according to InDegree, along with the number of outgoing links, the OutDegree. The standardized measurements for both the In- and Outdegree values (Nrm) are also provided in the table. For these Nrmdegrees, all of the degree counts have been expressed as percentages of the numbers of actors in the network, less one (ego) (Hanneman and Riddle 2005). Indegrees within the network range from 0 to 3,622 links (Mean $=134.5$ $\mathrm{SD}=401.2)$. Outdegrees range from 0 to 1,755 $($ Mean $=134.5 \mathrm{SD}=313.9)$. As evidenced by the larger number of Indegrees for the top blogs and the significant deviation, it is clear that only a few blogs are prominent, whereas most blogs receive limited attention. Among the top 30 blogs, none of the initial nodes can be found, although some domains did belong to the companies that write the focal blogs (Hp.com. Intel.com, download.intel.com).

The most prominent actor in the CSR network is addthis.com, which is a service linking content from various 


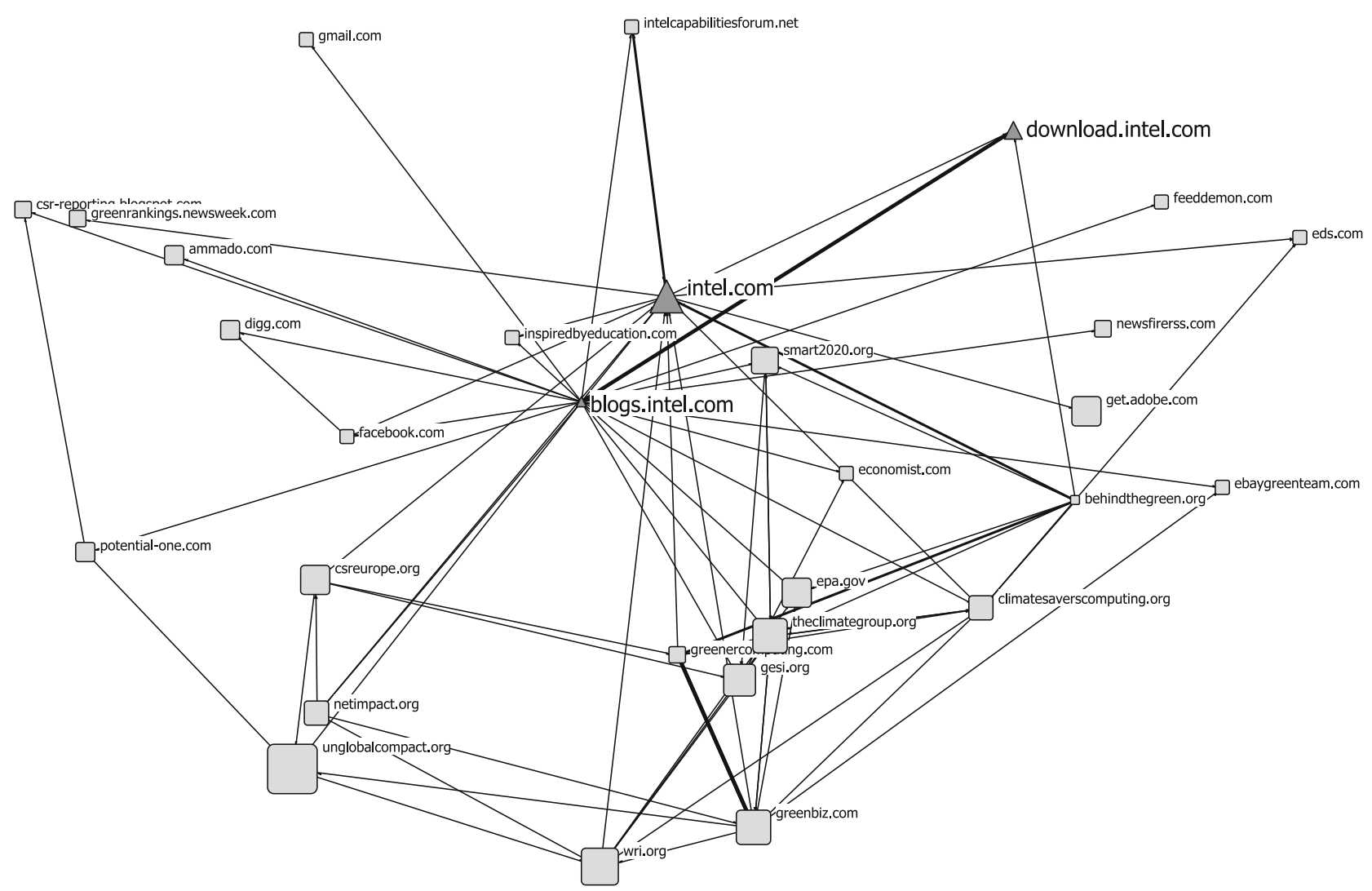

Fig. 2 Intel network (1-step neighborhood)

sites for social news (e.g., at the time, digg.com) and social networks (e.g., facebook.com). Each link provided by this service is a content recommendation provided by an individual for others. Additional highly engaged members of the CSR community are found in the surrounding environment of the focal nodes. Of interest from a structural perspective are sites such as greenbiz.com and greenercomputing.com, which not only have a high Indegree but also a large number of outgoing links and thus are actively connecting the community interested in these topics.

\section{Network Level}

Extending two iterations outwards from the three initial corporate CSR blogs, all of the websites that link or are linked to form a network. This network is not very dense, as every node connects to an average of only $1.3 \%$ of its possible relationships. This result, however, is not surprising, as the Internet itself follows a power law distribution (Albert et al. 1999). The power law distribution of the Internet states that a minority of sites receives the majority of incoming links, whereas a majority of sites receives only a minority of links. Additionally, as Burt (1982) argues, sparse networks with few redundant contacts provide more informational benefits, as they derive a greater diversity of information at a lower cost of access than a dense network. With that point in mind, the number of actual connections in relation to the number of potential connections (density) is a good indicator of the potential power distribution in the network. The loose connections present in power law patterns create a network in which only a few actors are involved in multiple interactions, whereas the majority is poorly connected and therefore does not have an influence on others but faces a low degree of constraints by others. Those few that are connected to almost everyone in the network have broad access to information and comparatively high influence on others, but their opportunities of free expression is limited, as failure is recognized by others immediately. For the network formed around our three initial blogs, the low density indicates that there are relatively few constraints on all actors except those involved in many relations on an individual level, the price to be paid for prominence and influence.

\section{Group Level}

Networks generally tend to be clustered. As these cliques might be particular in nature, it is important to investigate group patterns in addition to analyzing the individual and the network level. In Table 2, the ego-networks of each blog connected to the three initial blogs are shown. The 


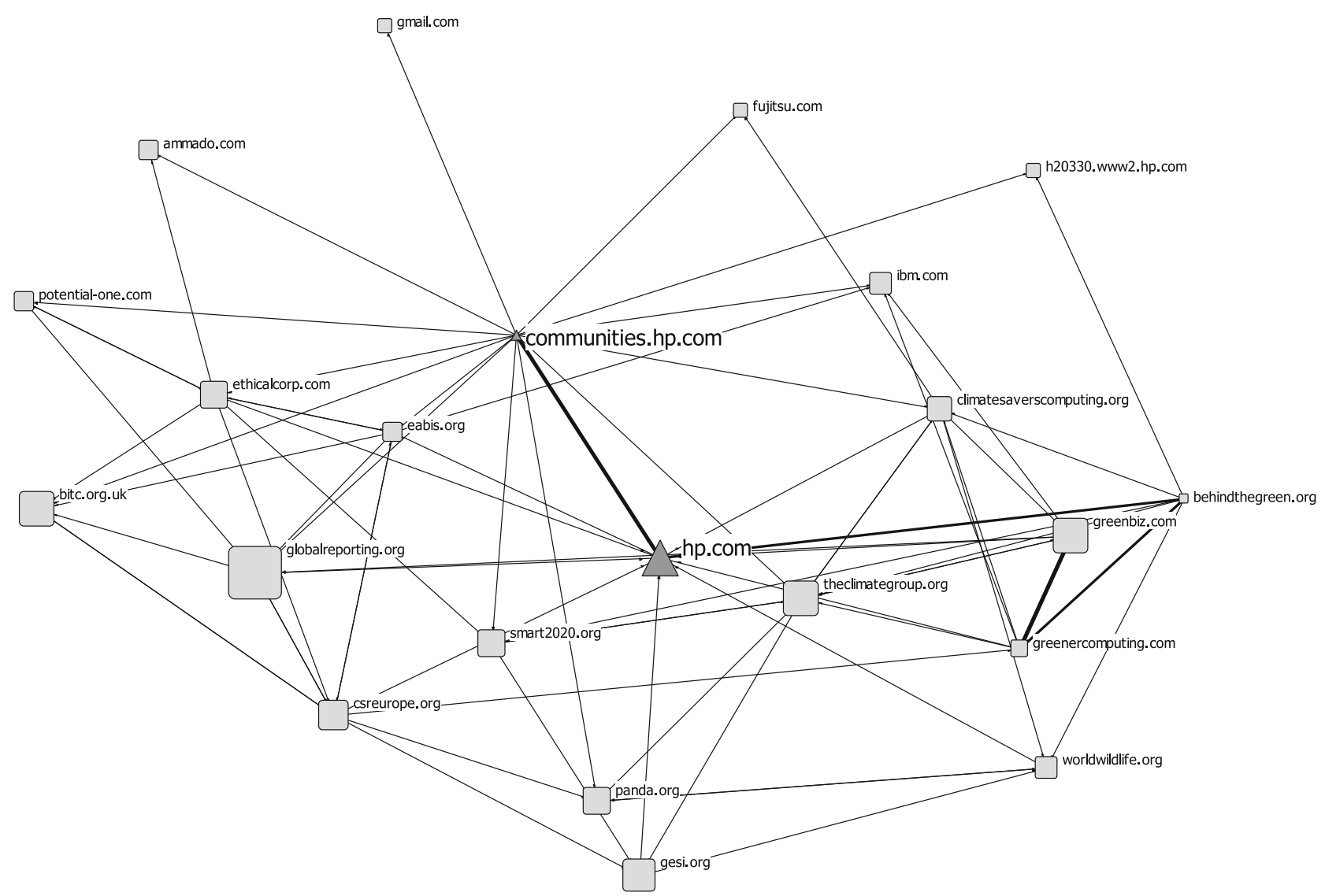

Fig. 3 Hewlett Packard network (1-step neighborhood)

data in the table include the size of the ego-network, indicating its importance, and density, an indicator of the constraints within the network. In contrast to our three investigated ego-networks, many others exhibit a higher density. A potential reason for this high density is that within these networks, the actors have more in common with each other, and this communality may be expressed through a large number of redundant links.

This said, the rather small ego networks indicate the existence of several sub-communities, each of which might follow different norms and foci. In contrast to the offline world, the mobilization of Internet-enabled social networks is not about mastering one large arena, as might be achieved with the assistance of a large NGO or mass media and their large audiences. In contrast, this mobilization resembles more entrances into several small discussion rounds that are hosted by different interest groups. Fieseler et al. (2010) have described these types of online relationships between an organization and its network as micro-dialogs. Internet discussions, such as discussions on blogs, might be driven by only a few or result in multiple conversations to which others pay little to no attention unless the right actors are involved. This distinction comes as a consequence of the power law distribution of links.
Only those blogs that have a high number of connections and, thus, a high potential to be referred are likely to be read. Conversely, poorly connected blogs are likely to be overlooked, despite their content and quality.

Finally, we concluded by determining which sub-groups were involved in which discussions and topics. A brief investigation of the blogs and their primary domain, as well as their form of organization, sheds light on this claim. Table 3 provides a short description of the weblogs and webpages appearing in Tables 1 and/or 2. Most websites belong to corporate entities (15), followed by membership organizations or associations (7) and NPOs (7). Several websites of governmental organizations (5) and intergovernmental organizations (5) were also discovered. Among the structurally most important blogs, only one belonged to a privately acting individual and one to an activist network.

\section{Discussion}

Preconditions

The above-described structural configuration of the network is not an even playing field, as every actor is 


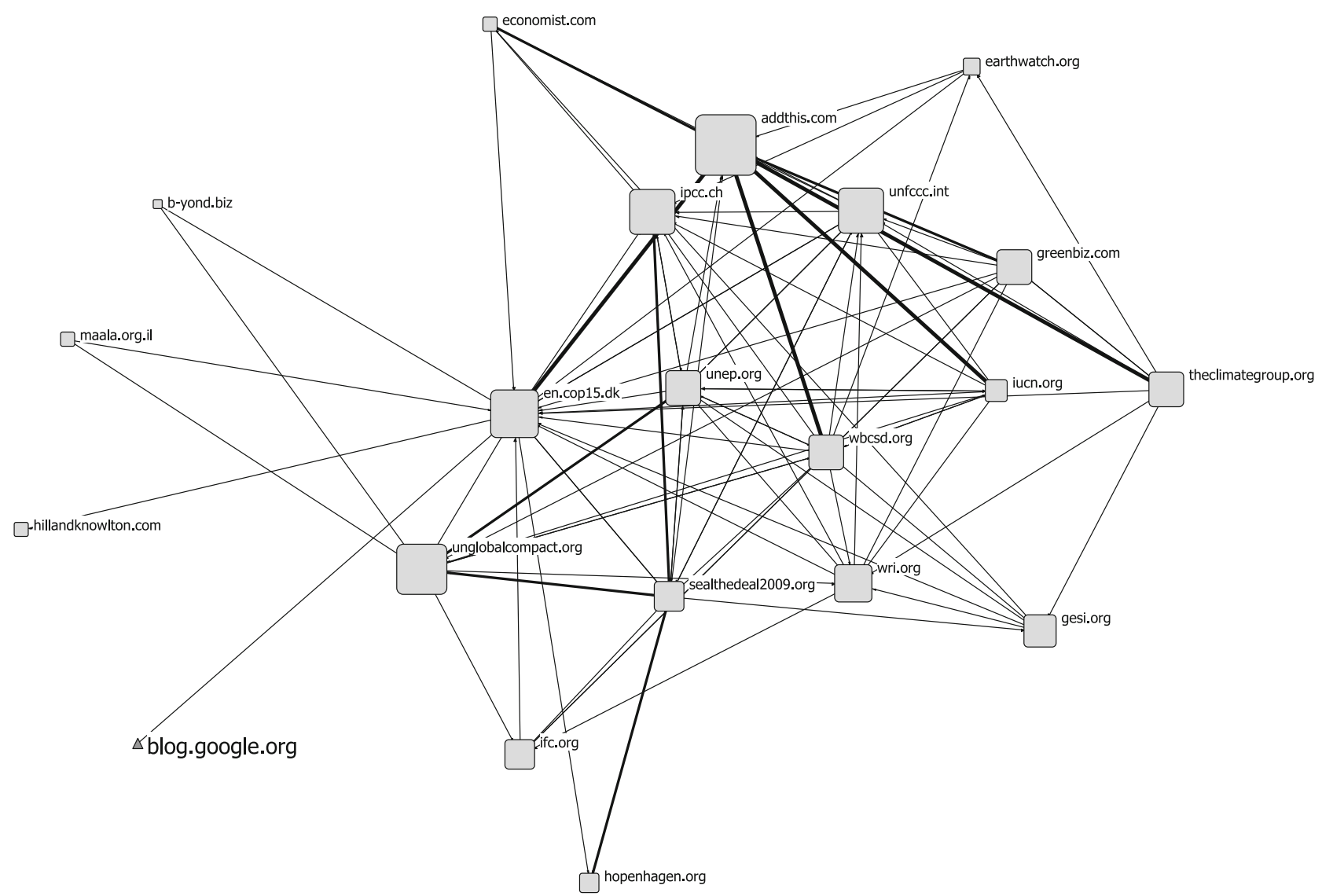

Fig. 4 Google network (2-step neighborhood)

Fig. 5 InDegree distribution (left) and Outdegree distribution (right)_logarithmic scale
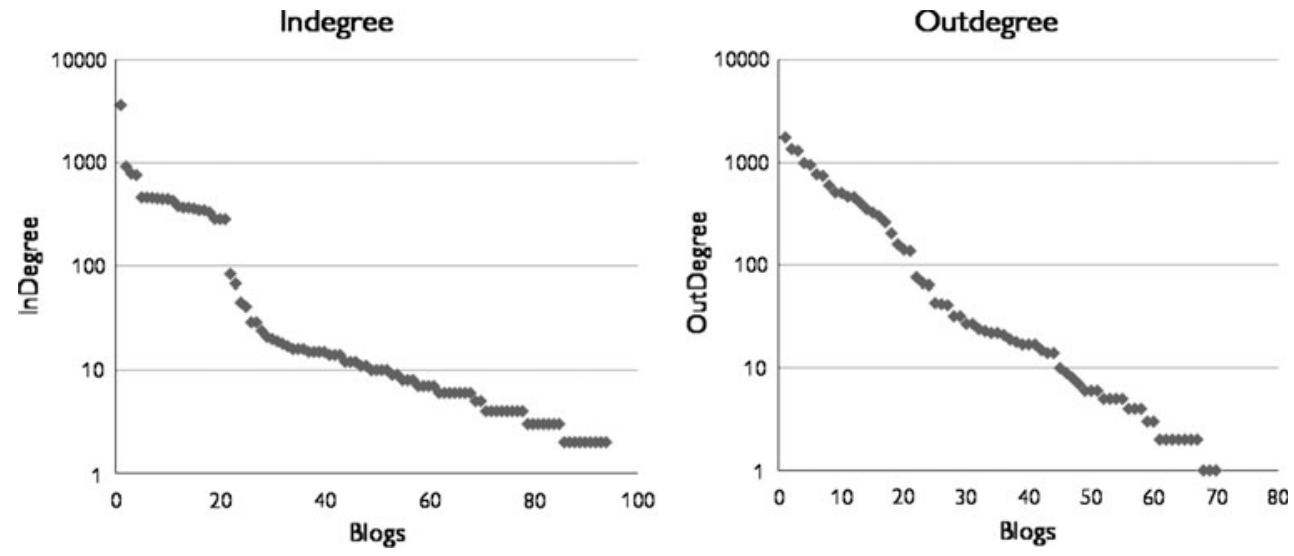

dependent on its surrounding structures in disseminating and gathering information via social media. For the three corporate blogs analyzed, there is, however, an observable inequality in terms of all three levels of structural capital in comparison with other network participants. At the individual level, there are other websites that are linked to much more than any of the three corporate blogs-for the same topic discussed, there are other parties that share a much greater part of the voice. In terms of the overall network, the CSR blogosphere appears to be rather scattered, with few interconnections. When examining subgroups within this network, there are a few information brokers that might give the spotlight to these corporate blogs, but they themselves are not in a position to wield power in any subgroup; rather, they are referred to on a punctual basis.

This relationship has implications for the structural social capital that both the corporate actors and the network interested in environmental and social issues as a whole can raise. Three types of benefits might arise from network 
Table 1 Top 30 Blogs according to InDegree

\begin{tabular}{|c|c|c|c|c|}
\hline Blog & $\begin{array}{l}\text { Indegree (Number } \\
\text { of incoming links) }\end{array}$ & $\begin{array}{l}\text { Outdegree (Number } \\
\text { of outgoing links) }\end{array}$ & $\begin{array}{l}\text { NrmInDeg (standardized } \\
\text { number of ingoing links) }\end{array}$ & $\begin{array}{l}\text { NrmOutDeg (standardized } \\
\text { number of outgoing links) }\end{array}$ \\
\hline addthis.com & 3,622 & 5 & 7.406 & 0.01 \\
\hline greenbiz.com & 921 & 767 & 1.883 & 1.568 \\
\hline hp.com & 785 & $\mathbf{0}$ & 1.605 & $\mathbf{0}$ \\
\hline greenercomputing.com & 761 & 740 & 1.556 & 1.513 \\
\hline bsr.org & 462 & 5 & 0.945 & 0.01 \\
\hline intel.com & 460 & 15 & 0.941 & 0.031 \\
\hline csrwire.com & 458 & 17 & 0.936 & 0.035 \\
\hline get.adobe.com & 451 & 0 & 0.922 & 0 \\
\hline energy.gov & 446 & 3 & 0.912 & 0.006 \\
\hline epa.gov & 445 & 0 & 0.91 & 0 \\
\hline download.intel.com & 428 & $\mathbf{0}$ & 0.875 & $\mathbf{0}$ \\
\hline unglobalcompact.org & 379 & 987 & 0.775 & 2.018 \\
\hline wri.org & 368 & 27 & 0.752 & 0.055 \\
\hline hopenhagen.org & 367 & 0 & 0.75 & 0 \\
\hline globalreporting.org & 360 & 42 & 0.736 & 0.086 \\
\hline ipcc.ch & 348 & 2 & 0.712 & 0.004 \\
\hline unep.org & 347 & 137 & 0.71 & 0.28 \\
\hline unpri.org & 331 & 43 & 0.677 & 0.088 \\
\hline att.com & 286 & 4 & 0.585 & 0.008 \\
\hline johnsoncontrols.com & 285 & 1 & 0.583 & 0.002 \\
\hline emc.com & 284 & 299 & 0.581 & 0.611 \\
\hline sealthedeal2009.org & 84 & 944 & 0.172 & 1.93 \\
\hline en.cop15.dk & 68 & 596 & 0.139 & 1.219 \\
\hline unfecc.int & 45 & 32 & 0.092 & 0.065 \\
\hline marcgunther.com & 41 & 1,352 & 0.084 & 2.764 \\
\hline energystar.gov & 29 & 1,299 & 0.059 & 2.656 \\
\hline theclimategroup.org & 29 & 402 & 0.059 & 0.822 \\
\hline netimpact.org & 24 & 21 & 0.049 & 0.043 \\
\hline linkedin.com & 21 & 0 & 0.043 & 0 \\
\hline corporateregister.com & 20 & 67 & 0.041 & 0.137 \\
\hline
\end{tabular}

Domains belonging to focal companies are represented in bold

structure: the access to and timing of information, and referrals (Burt 1982).

The term "access" refers to the receipt of valuable information and knowledge of who can use it, and it also identifies the role of networks in providing efficient information-screening and distribution processes for the members of those networks. The effective screening and distribution of ideas is bound less to the number of network members than to the existence of a power law distribution. As access to such information networks and their information is not limited, it is important that certain actors in the network engage and become trusted sources, thereby serving as valuable filters in the process of information dissemination. Conversely, the promotion of any idea in the network is dependent on those brokers. Here, it became evident that corporate actors were unable to attain this position.

The "timing" of informational flows refers to the ability of personal contacts to provide information sooner than it becomes available to people without such contacts. This timing may well increase the anticipated value of such information. Communication networks based on blogs are not bound by a certain timeframe. Therefore, they may evolve over time, and a long-term perspective of relationship development is more appropriate. As corporate engagement efforts are a rather recent phenomenon online, corporations might become a more relevant part of the conversation with time-however, this is most likely dependent on assistance from other parties. 
Table 2 Top 30 Ego-networks

\begin{tabular}{|c|c|c|c|c|}
\hline $\mathrm{B} \log$ & $\begin{array}{l}\text { Number of blogs within } \\
\text { the Ego-network }\end{array}$ & $\begin{array}{l}\text { Links within } \\
\text { the network }\end{array}$ & $\begin{array}{l}\text { Number of potential links } \\
\text { among the actors }\end{array}$ & Density \\
\hline greenbiz.com & 41 & 114 & 1,640 & 6.95 \\
\hline globalreporting.org & 29 & 108 & 812 & 13.3 \\
\hline wbcsd.org & 28 & 134 & 756 & 17.72 \\
\hline wri.org & 26 & 96 & 650 & 14.77 \\
\hline addthis.com & 24 & 60 & 552 & 10.87 \\
\hline unglobalcompact.org & 24 & 100 & 552 & 18.12 \\
\hline ethicalcorp.com & 22 & 34 & 462 & 7.36 \\
\hline potential-one.com & 21 & 45 & 420 & 10.71 \\
\hline blogs.intel.com & 21 & 17 & 420 & 4.05 \\
\hline csrwire.com & 20 & 67 & 380 & 17.63 \\
\hline en.cop15.dk & 20 & 72 & 380 & 18.95 \\
\hline climatesaverscomputing.org & 20 & 39 & 380 & 10.26 \\
\hline netimpact.org & 19 & 60 & 342 & 17.54 \\
\hline gesi.org & 19 & 29 & 342 & 8.48 \\
\hline unfecc.int & 18 & 68 & 306 & 22.22 \\
\hline behindthegreen.org & 18 & 22 & 306 & 7.19 \\
\hline theclimategroup.org & 17 & 43 & 272 & 15.81 \\
\hline bsr.org & 16 & 64 & 240 & 26.67 \\
\hline csreurope.org & 16 & 51 & 240 & 21.25 \\
\hline intel.com & 15 & 20 & 210 & 9.52 \\
\hline ipcc.ch & 15 & 51 & 210 & 24.29 \\
\hline sealthedeal2009.org & 15 & 53 & 210 & 25.24 \\
\hline communities.hp.com & 15 & 22 & 210 & 10.48 \\
\hline b-yond.biz & 15 & 18 & 210 & 8.57 \\
\hline unep.org & 14 & 63 & 182 & 34.62 \\
\hline greenercomputing.com & 14 & 34 & 182 & 18.68 \\
\hline panda.org & 14 & 21 & 182 & 11.54 \\
\hline marcgunther.com & 13 & 28 & 156 & 17.95 \\
\hline eabis.org & 13 & 33 & 156 & 21.15 \\
\hline corporateregister.com & 12 & 34 & 132 & 25.76 \\
\hline
\end{tabular}

Domains belonging to focal companies are represented in bold

Third, here, referrals refer to reputational endorsement of the actors involved, which influences the anticipated value of the combination and exchange as well as the motivation for such exchange (see Granovetter 1973; Putnam 2000). Generally, with referrals, valuable information emanates from trustful sources or is referred by trustful sources, whereby a source becomes trustful in the first place if many actors in the network refer (to) the source over time. An indicator of a community's acceptance of a source is the number of referrals from others in the network, which can be measured by the number of incoming links (in Figs. 1, 2, 3, 4, the size of each node/actor is visualized according to the number of incoming links).

Returning to the corporate blogs, the network in which they are embedded determines norms and rules, as well as the structural constraints of each of the three actors. The price for entry in a network (in this case, the online blogosphere interested in CSR matters) is a commitment to the rules and norms of the community, which in social media, typically includes transparency and openness (Cenite et al. 2009), as well as (generalized) reciprocity (McLure Wasko and Faraj 2005). The third norm, reciprocity of relationships, might be particularly new to the corporate sector, as it must increasingly cope with a large number of interconnected individuals who were previously merely an atomized audience.

Engaging audiences in CSR via social media entails not only access to highly engaged communities but also a commitment to seriously considering the comments of the readership and their surrounding networks. Disregarding these norms may lead to sanctions by the community, such as ignorance, the removal of links, and bad word of mouth 
Table 3 Short description of identified network actors

\begin{tabular}{|c|c|c|}
\hline & Short description & Legal form \\
\hline addthis.com & Bookmarking websites & Company \\
\hline att.com & AT\&T homepage & Company \\
\hline behindthegreen.org & Digital Energy Solution Campaign (DESC) & Association \\
\hline blogs.intel.com & Blogging platform from Intel & Company \\
\hline bsr.org & Business for Social Responsibility (BSR) & Association \\
\hline b-yond.biz & Consulting company & Company \\
\hline climatesaverscomputing.org & Focus on eco-conscious consumers and businesses & NPO \\
\hline communities.hp.com & Blogging platform from Hewlett Packard & Company \\
\hline corporateregister.com & Database for Corporate Responsibility Reports & Organization \\
\hline csreurope.org & Business network for corporate social responsibility & Association \\
\hline csrwire.com & Service specializing in news on CSR & Association \\
\hline download.intel.com & Download platform from Intel & Company \\
\hline eabis.org & Academy of Business in Society (EABIS) & Association \\
\hline emc.com & IT Company & Company \\
\hline en.cop15.dk & $\begin{array}{l}\text { Danish government's host country website for UN Climate } \\
\text { Change Conference } 2009\end{array}$ & GO \\
\hline energy.gov & U.S. Department of Energy & GO \\
\hline energystar.gov & U.S. Department of Energy & GO \\
\hline epa.gov & U.S. Environmental Protection Agency & GO \\
\hline ethicalcorp.com & Magazine about responsible business & Company \\
\hline gesi.org & Initiative for sustainable development in ICT industry & NPO \\
\hline globalreporting.org & Global Reporting Initiative (GRI) & NPO \\
\hline greenbiz.com & Service specializing in news on CSR & Company \\
\hline greenercomputing.com & Subsite of greenbiz.com & Company \\
\hline hopenhagen.org & $\begin{array}{l}\text { Campaign website about UN Climate } \\
\text { Change Conference } 2009\end{array}$ & $\begin{array}{l}\text { UN collaboration } \\
\text { with Ad-Agencies }\end{array}$ \\
\hline hp.com & ICT Company Intel & Company \\
\hline intel.com & ICT Company Intel & Company \\
\hline ipcc.ch & Intergovernmental Panel on Climate Change & UN \&WMO \\
\hline johnsoncontrols.com & Industry Company Johnson Controls & Company \\
\hline linkedin.com & Social network sites primarily used for business contacts & Company \\
\hline marcgunther.com & Private weblog of a journalist, speaker, writer and consultant & Individual \\
\hline netimpact.org & NPO focused on sustainability & NPO \\
\hline panda.org & World Wildlife Fund (WWF) site & NPO/NGO \\
\hline potential-one.com & Consulting Company with focus on CSR & Company \\
\hline sealthedeal2009.org & UN campaign & UN \\
\hline theclimategroup.org & NPO focused on sustainability & NPO \\
\hline unep.org & United Nations Environment Programme & GO \\
\hline unfccc.int & United Nations Framework Convention on Climate Change & UN \\
\hline unglobalcompact.org & Policy initiative for businesses & UN \\
\hline unpri.org & Principles for Responsible Investment & UNEP, UN \\
\hline wbcsd.org & World Business Council for Sustainable Development (WBCSD) & Association \\
\hline wri.org & WIR: World Resource Institute & NPO \\
\hline
\end{tabular}

publicity generated by activist-led campaigns. These outcomes might appear unexpected within large and disperse networks such as the Internet. However, norms, such as solidarity and strong ties, are not uncommon (Kittur et al.
2006). Multi-user collaboration and loose corporation are a result of early engagement and the strong relations of only a few individuals. Organizations that have been confronted with an atomized stakeholder sphere now face networks of 
individuals who understand their influence on the public agenda, as information can be shared easily within those large networks of loosely joined actors. What this process entails for the capitalization of social capital will be discussed next.

\section{Capitalization}

In regard to the possible capitalizations of their networks, it must be noted again that all three blogs had a rather marginal influence at the individual, network, and subgroup levels. However, it must be noted that these conclusions are based on a special method of data collection, which primarily focused on larger blogs and excluded those with domains from bloghosters such as blogger.com or typepad.com. It can be assumed that each blog is followed by numerous smaller blogs (cf. Fieseler et al. 2010).

As a result, social software applications reduce incumbent forces' potential to capitalize on social capital and to influence policy to a higher extent than it is possible to indicate with a technical analysis, while opening avenues for new actors. The Internet itself has little to no formal hierarchy. Everyone in the western hemisphere with Internet access is free to publish his or her thoughts, constrained by very few gatekeeping mechanisms. Bloggers, for example, can theoretically express their ideas to a broad audience with minimal effort. Therefore, stakeholder audiences can no longer be conceptualized as passive receivers of information. Rather, blogs, wikis, and social networks share the ability to transform users into producers and disseminators of information. They provide platforms for the spontaneous individual and collective publication of information, opinions, or mere musings. As such, social media undermines the former sense-making monopoly of the traditional players and opens the arena for loosely bound activists that can more easily connect, collaborate, and influence organizational policy.

From a social networks perspective, these actors have high status and are well respected within the community. Such information brokers are the opinion leaders in today's network age (Farrell and Drezner 2008). If less prominent actors intend to benefit from their prominence, they must borrow social capital from these structurally important actors. In practical terms, it is much easier to promote ideas within the network with these prominent actors' assistance. In addition, it is much more difficult to reach and convince a larger audience without these players. However, and in contrast to the offline world, those structurally important players are not necessarily the large activist organizations recognized in the offline world. Many of these players might address a special and narrow range of topics and might not be as transparent to companies engaging in online disclosures as organizations that are known to companies in the offline world. Therefore, metaphorically speaking, the borrowing of social capital reputation from these partners could lead to misunderstandings or unintended conflicts.

A case in point in the data is the Google CSR blog (see Fig. 4), which is heavily dependent on only a few actors, which means that conversations in this network are only possible with the goodwill of those actors. Particularly in this case, borrowing social capital might be a potential strategy recommendation from a structural point of view. For example, social capital can be borrowed by establishing relations to more prominent actors and through involvement in their discussions. In this way, less prominent bloggers will be visible to larger public spheres. In addition, the creation of relations that guarantee several redundant points of access to networks could be considered additional advice. In practice, this creation of relations means not only engaging by posting comments on one's blog but also participating in blog conversation through commentary and links to central actors of defined subcommunities. Recognition and goodwill originating from these focal actors will lead to a better standing within the defined sub-community. However, this mechanism also works in the other direction if the expectations of the community are not met.

\section{Effects}

Social network mobilization offers potential returns. The outcomes of structural positions are assets such as wealth, power, and reputation. Although wealth and power are classic associations of any form of capital, reputation shifts attention to other relevant outcomes of social network mobilization. From a social capital perspective, reputations involve positive or negative opinions about an individual or an organization in a social network (Lin 1999, 19).

The disintermediation process imminent in social media has effects on the returns of the incumbent holders of social capital, as well as on those of newly emerging constituencies. With information advantages shrinking because of social software, it becomes more difficult for these actors to influence the flow of information and to exert power through social influence. Traditionally, those with access to unique and valuable information have had opportunities to exploit such information for their own benefit (Granovetter 1973). Social software and Web 2.0 have made access to information much easier. Conversely, one must admit that the possibilities arising from such technologies and services cannot level the playing field on their own. Cammaerts (2008) emphasizes that if personal social networks migrate online, differentiation, hierarchies, and control might migrate online as well. 
It must be noted again that that at the time of writing, the corporate actors that we analyzed were among the most engaged in communicating their CSR activities via online channels. We observe three possible strategies. As they stand, the influence of their engagement efforts is marginal at best. In this case, the strategy is a conscious one, involving staying small and off the radar. Although with this method, there are few mistakes to be made with the engagement itself, it has little to no effect on making the firms' standpoint on green and social computing heard; in a sense, it is communicating for communication's sake. There are two additional options a corporate actor might want to pursue. First, s/he could attempt to obtain more influence in a network through the borrowing of social capital from another actor in the network. This method would entail approaching one of the more important players with more embeddedness and thus impact. Whether these actors are likely to cooperate, especially when there is (perceived) discrepancy between voice and act, is doubtful, not least because of fear for one's own reputation within the network. To a degree, therefore, corporations seeking this option must play by the rules of these brokers and might face criticism on these platforms. Finally, there is the option of focusing even more on a thematic niche and becoming the foremost authority in that niche-however, as green IT is already a niche topic within CSR, whether this might lead in actual effect to a different outcome if it can be pursued at all remains doubtful.

\section{Conclusions and Future Research: Social Media and Stakeholder Engagement}

By not only accepting but also actively involving Web 2.0 applications such as blogs, wikis, social networks, and online communities, CSR can become an even more strategic management function. Stakeholders could be engaged in decision-making processes and in every step of their implementation. Various instruments could be targeted at specific stakeholders during different steps of this process: wikis for employees, blogs for journalists, and social networks for users or community members. Of course, companies can no longer shield themselves from the involvement of stakeholders in any way. The only question is whether they are willing to actively shape their interactions with stakeholder groups, or rather, be dragged along by the dynamic of Web 2.0 participation.

It is, however, important to note that the audiences of online discussion platforms are rather small in comparison to the mass media audience. In contrast to the large and predominately passive audience of the mass media, social media only attracts those who actively look for conversation and engage in online discussions. This scenario is both positive and negative, as social media might not have a direct impact on the larger public sphere. Instead, social media can indirectly reach this larger sphere through opinion leaders.

The motivation for more interaction with stakeholders stems not only from corporate goodwill but also from changing stakeholder demands. Stakeholders are becoming increasingly more critical, especially with regard to social and environmental issues. The conclusions derived from the case studies can only be a first step toward a richer and more complex theory, as proposed by Eisenhardt and Graebner (2007). Future research in the field of web-based CSR, also with regard to micro-dialogic processes at different levels, might prove very worthwhile in better understanding and managing social responsibility in ever more networked societies.

Beginning with Bourdieu (1977, 1986), scholars have examined strategies of social capital acquisition and investment. In a Web 2.0 environment, these strategies become much more transparent through platforms such as blogs and social networking sites. Relations among actors can be collected, visualized, and monitored much more easily to facilitate better understanding of individual positions and their effects on social capital preconditions. The Internet's open and transparent character impedes the unilateral accumulation of social capital. Because of this impediment, strategies without respect for the rules and norms of the network may prove to be detrimental. Further research into the implicit rules of networks, as well as the mechanism and practices of collective sanctions, should be worthwhile in explaining adequate strategies for firms within social networks in a more democratic media space.

Second, social capital, or to be more precise, social relations require maintenance, as ties may weaken as a result of relational atrophy (Cheal 1988). Relationships in general and social media in particular demand frequent updates to prevent atrophy. The more channels that are employed, the better this effort will be. Content and content distribution is best understood as an invitation to dialog that is initiated by the focal actor. It is not only worthwhile to analyze this issue from a structural point of view but also necessary to perform analysis through a longitudinal investigation of the evolution network structures over time. Existing theories taken from marketing (for diffusion theories in marketing, see Van den Bulte and Joshi 2007; Bass 2004), network simulation (among others: Watts and Dodds 2007) and social capital theory (Burt 1999, 2000, 2005) could facilitate either the tracking or simulation of diffusion processes of social media and their impact on reputation management, as well as a better understanding of how social capital is acquired and spent over time.

Third, social networks reside in individuals as well as in mutual ties. As a result, if one party defects the relationship, social capital vanishes. In consequence, it is important 
to not only build relations but also maintain them. The offering of updates is only one form, whereas valuing and honoring user efforts on corporate platforms is another. Although studies have thus far investigated why users engage online (McLure Wasko and Faraj 2005, Trammell and Keshelashvili 2005; Stefanone and Jang 2007; Cenite et al. 2009), it is currently still unclear why users are willing to engage on corporate platforms and what they demand in exchange for their engagement.

Finally, social capital resembles a collective good in that one can own social capital, but not in the sense of private property because it depends on ties between individuals (Coleman 1988). Organizations must be aware that their engagement efforts are only an offer to the surrounding network. As is true with every offer, it must be convincing and attractive to the counterpart. For this reason, research into the dialogic potential of weblogs could profit from not only the investigation of static website designs (Kent et al. 2003; Kent and Taylor 1998), but also factors that drive information exchange as a basis for mutual dialogs.

As such, Social Media facilitate and structure more direct engagement between companies and stakeholders. Social media may lead to conversations that involve the raising of issues, discussions on priorities, and solutions and implementations. For these conversations to occur, corporations must realize that they are embedded in an online network structure of interested parties in which at this point in time, they are mere voices in a discussion of which they are not yet an equal part.

\section{References}

Adler, P. S., \& Kwon, S. W. (2000). Social capital: The good, the bad, and the ugly. Knowledge and social capital: Foundations and applications, 2000, 89-115.

Adler, P. S., \& Kwon, S. (2002). Social capital: Prospects for a new concept. Academy of Management Review, 27(1), 17-40.

Albert, R., Jeong, H., \& Barabasi, A. L. (1999). Diameter of the World-Wide Web. Nature, 401(9), 130-131.

Bass, F. M. (2004). A new product growth for model consumer durables. Management Science, 50(12), 1825-1832.

Beaudion, C. E., \& Tao, C. C. (2007). Benefiting from social capital in online support groups: An empirical study of cancer patients. CyberPsychology and Behavior, 10(4), 587-590.

Bennett, W. L., \& Iyengar, S. (2008). A new era of minimal effects? The changing foundations of political communication. Journal of Communication, 58(4), 707-731.

Berthon, P. R., Pitt, L. F., Plangger, K., \& Shapiro, D. (2012). Marketing meets Web 2.0, social media, and creative consumers: Implications for international marketing strategy. Business Horizons, 55(3), 261-271.

Blood, R. (2004). How blogging software reshapes the online communication. Communications of the ACM, 47(12), 53-55.

Borgatti, S. P., Everett, M. G., \& Freeman, L. C. (2002). Ucinet for Windows: Software for social network analysis.
Bourdieu, P. (1977). Outline of a theory in practice. Cambridge: Cambridge University Press.

Bourdieu, P. (1986). Forms of capital. In J. G. Richardson (Ed.), Handbook of theory and research for the sociology of education. New York: Greenwood Press.

Boyd, D. M., \& Ellison, N. B. (2007). Social network sites: Definition, history, and scholarship. Journal of Computer Mediated Communication, 13(1), 210-230.

Bruns, A. (2007). Methodologies for mapping the blogosphere: An exploration using the issue crawler tool. First Monday, 12(1). doi: $10.5210 \% 2$ Ffm.v12i5.1834.

Burt, R. S. (1982). Toward a structural theory of action: Network models of social structure, perception, and action. New York: Academic Press.

Burt, R. S. (1997). The contingent value of social capital. Administrative Science Quarterly, 42(2), 339-365.

Burt, R. S. (1999). The social capital of opinion leaders. The Annals of the American Academy of Political and Social Science, 566, $37-54$.

Burt, R. S. (2000). The network structure of social capital. Research in Organizational Behavior, 22, 345-423.

Burt, R. S. (2005). Brokerage and closure. New York: Oxford University Press.

Cammaerts, B. (2008). Critiques on the participatory potentials of Web 2.0. Communication, Culture and Critique, 1(4), 358-377.

Cenite, M., Detenber, B. H., Koh, A. W. K., \& Lim, A. L. H. (2009). Doing the right thing online: A survey of bloggers ethical beliefs and practices. New Media and Society, 11(4), 575-597.

Cheal, D. (1988). The gift economy. London/New York: Routledge.

Chen, S. (2009). Corporate responsibilities in internet-enabled social networks. Journal of Business Ethics, 90(4), 523-536.

Coleman, J. S. (1988). Social capital in the creation of human capital. American Journal of Sociology, 94(1), S95-S120.

Coleman, J. S. (1990). Foundations of social theory. Boston, MA: Harvard University Press.

Dahlgren, P. (2005). The Internet, public spheres, and political communication: Dispersion and deliberation. Political Communication, 22(2), 147-162.

Dore, R. (1983). Goodwill and the spirit of market capitalism. British Journal of Sociology, 34(4), 459-482.

Eisenhardt, K. M., \& Graebner, M. E. (2007). Theory building from cases: Opportunities and challenges. Academy of Management Journal, 50(1), 25-32.

Ellison, N. B., Steinfield, C., \& Lampe, C. (2007). The benefits of facebook "friends:" Social capital and college students use of online social network sites. Journal of Computer-Mediated Communication, 12(4), 1143-1168.

Etter, M., \& Fieseler, C. (2010). On relational capital in social media. Studies in Communication Sciences, 10(2), 167-189.

Farrell, H., \& Drezner, D. W. (2008). The power and politics of blogs. Public Choice, 134(1), 15-30.

Ferrary, M. (2003). The gift exchange in the social networks of Silicon Valley. California Management Review, 45(4), 120-138.

Field, J. (2003). Social capital. London/New York: Routledge.

Fieseler, C., Fleck, M., \& Meckel, M. (2010). Corporate social responsibility in the blogosphere. Journal of Business Ethics, 91(4), 599-614.

Flap, H. D., \& De Graaf, N. D. (1988). Social capital in the reproduction of inequality. Comparative Sociology of Family, Health and Education, 20, 6179-6202.

Freeman, L. C. (1979). Centrality in social networks: Conceptual clarification. Social Networks, 1(3), 215-239.

Gil De Zuniga, H., Veenstra, A., Vraga, E., \& Shah, D. (2010). Digital democracy: Reimagining pathways to political üarticipation. Journal of Information Technology Politics, 7(1), 36-51. 
Golder, S. A., \& Huberman, B. A. (2006). Usage patterns of collaborative tagging systems. Journal of Information Science, 32(2), 198-208.

Granovetter, M. S. (1973). The strength of weak ties. The American Journal of Sociology, 78(6), 1360-1380.

Granovetter, M. (1985). Economic action and social structure: The Problem of Embeddedness. American Journal of Sociology, 91(3), 481-510.

Hampton, K. N. (2003). Grieving for a lost network: Collective action in a wired Suburb. The Information Society, 19(5), 417-428.

Hanneman, R. A., \& Riddle, M. (2005). Introduction to social network methods. Riverside, CA: University of California.

Hargittai, E. (2010). Digital na(t)ives? Variation in internet skills and uses among members of the "Net Generation". Sociological Inquiry, 80(1), 92-113.

Hargittai, E., \& Walejko, G. (2008). The participation divide: Content creation and sharing in the digital age. Information, Communication and Society, 11(2), 239-256.

Heide, J. B., \& Miner, A. S. (1992). The shadow of the future: Effects of anticipated interaction and frequency of contact on buy-seller cooperation. Academy of Management Journal, 35(2), 265-291.

Hill, C. W. L. (1990). Cooperation, opportunism, and the invisible hand: Implications for transaction cost theory. Academy of Management Review, 15(3), 500-513.

Kavanaugh, A. L., \& Patterson, S. J. (2001). The impact of community computer networks on social capital and community involvement. American Behavioral Scientist, 45(3), 496-509.

Kavanaugh, A., Carroll, J. M., Rosson, M. B., Zin, T. T., \& Reese, D. D. (2005). Community networks: Where offline communities meet online. Journal of Computer-Mediated Communication, $10(4), 442-464$.

Kent, M. L., \& Taylor, M. (1998). Building dialogic relationships through the World Wide Web. Public Relations Review, 24(3), 321-334.

Kent, M. L., Taylor, M., \& White, W. J. (2003). The relationship between Web site design and organizational responsiveness to stakeholders. Public Relations Review, 29(1), 63-77.

Kittur, A., Chi, E., Pendleton, B. A., Suh, B., \& Mytkowicz, T. (2006). Power of the few vs. wisdom of the crowd: Wikipedia and the rise of the bourgeoisie. World Wide Web, 1(2), 19.

Knoke, D., \& Burt, R. S. (1983). Prominence. In R. S. Burt \& M. J. Minor (Eds.), Applied network analysis: A methodological introduction (pp. 195-222). Beverly Hills, LA: Sage Publications.

Kolari, P., Java, A., \& Finin, T. (2006). Characterizing the Splogosphere. Working Paper. http://www.blogpulse.com/ www2006-workshop/papers/splogosphere.pdf.

Lawrence, E., Sides, J., \& Farrell, H. (2010). Self-segregation or deliberation? Blog readership, participation, and polarization in American politics. Perspectives on Politics, 8(01), 141-157.

Lin, N. (1999). Building a network theory of social capital. Connections, 22(1), 28-51.

Louie, A. W. M. (2007). Designing avatars in virtual worlds: How free are we to play Superman. Journal of Internet Law, 11(5), $3-12$.

Mathwick, C., Wiertz, C., \& De Ruyter, K. (2007). Social capital production in a virtual P3 community. Journal of Consumer Research, 34(6), 832-849.

McBain, R. (2005). Appreciating the value of human and social capital. Henley Manager Update, 16(3), 1-9.

McLure Wasko, M., \& Faraj, S. (2005). Why should I share? Examining social capital and knowledge contribution in electronic networks of practice. MIS Quarterly, 29(1), 35-57.

Morozov, E. (2011). The net delusion: The dark side of internet freedom. New York: Public Affairs.
Nahapiet, J., \& Ghoshal, S. (1998). Social capital, intellectual capital, and the organizational advantage. Academy of Management Review, 23(2), 242-266.

Nie, N. H., Miller, I. D. W., Golde, S., Butler, D. M., \& Winneg, K. (2010). The World Wide Web and the U.S. political news market. American Journal of Political Science, 54(2), 428-439.

Park, H. W. (2003). Hyperlink network analysis: A new method for the study of social structure in the web. Connections, 25(1), 49-61.

Parkhe, A. (1993). Strategic alliance structuring: A game theoretic and transaction cost examination of interfirm cooperation. The Academy of Management Journal, 36(4), 794-829.

Pasek, J., More, E., \& Romer, D. (2009). Realizing the social internet? Online social networking meets offline civic engagement. Journal of Information Technology Politics, 6(3), 197-215.

Pitt, L. F. (2012). Web 2.0, social media and creative consumersImplications for public policy; introduction to the special edition. Journal of Public Affairs, 12(2), 105-108.

Portes, A. (1998). Social capital: Its origins and applications in modern sociology. Annual Review of Sociology, 24(1), 1-24.

Prahalad, C. K., \& Ramaswamy, V. (2004). The future of competition. Boston, MA: Harvard Business School Press.

Putnam, R. (2000). Bowling alone: The collapse and revival of American community. New York: Simon Schuster.

Rushkoff, D. (2011). Program or be programmed: Ten commands for a digital age. Berkeley, CA: Soft Skull Press.

Sandefur, R. L., \& Laumann, E. O. (1998). A paradigm for social capital. In E. L. Lesser (Ed.), Knowledge and social capital: Foundations and applications. Boston, MA: Butterworth Heinemann.

Scheufele, D. A., Hardy, B. W., Brossard, D., Waismel Manor, I. S., \& Nisbet, E. (2006). Democracy based on difference: Examining the links between structural heterogeneity, heterogeneity of discussion networks, and democratic citizenship. Journal of Communication, 56(4), 728-753.

Scott, J. (2000). Social network analysis: A handbook. London: Sage Publications.

Spence, L. J., Schmidpeter, R., \& Habisch, A. (2003). Assessing social capital: Small and medium sized enterprises in Germany and the UK. Journal of Business Ethics, 47(1), 17-29.

Spinellis, D., \& Louridas, P. (2008). The collaborative organization of knowledge. Communications of the ACM, 51(8), 68-73.

Stefanone, M. A., \& Jang, C. Y. (2007). Writing for friends and family: The interpersonal nature of blogs. Journal of ComputerMediated Communication, 13(1), 123-140.

Steinfield, C., Ellison, N., \& Lampe, C. (2008). Social capital, selfesteem, and use of online social network sites: A longitudinal analysis. Journal of Applied Developmental Psychology, 29(6), 434-445.

Tapscott, D., \& Williams, A. D. (2006). Wikinomics: How mass collaboration changes everything. New York: Penguin.

Towner, T. L., \& Dulio, D. A. (2011). An experiment of campaign effects during the YouTube election. New Media and Society, 13(4), 626-644

Trammell, K. D., \& Keshelashvili, A. (2005). Examining the new influencers: A self-presentation study of A-List blogs. Journalism and Mass Communication Quarterly, 82(4), 968-982.

Tsai, W., \& Ghoshal, S. (1998). Social capital and value creation: The role of intrafirm networks. Academy of Management Journal, 41(4), 464-476.

Van den Bulte, C., \& Joshi, Y. V. (2007). New product diffusion with influentials and imitators. Marketing Science, 26(3), 400-421.

Warr, W. A. (2008). Social software: fun and games, or business tools? Journal of Information Science, 34(4), 591-604. 
Wasserman, S., \& Faust, K. (1994). Social network analysis methods and applications. Cambridge: Cambridge University Press.

Wattal, S., Schuff, D., Mandviwalla, M., \& Williams, C. B. (2010). Web 2.0 and politics: The 2008 US presidential Election and an e-politics research agenda. MIS Quarterly, 34(4), 669-688.

Watts, D. J., \& Dodds, P. S. (2007). Influentials, networks, and public opinion formation. Journal of consumer research, 34(4), $441-458$

Wellman, B., Haase, A. Q., Witte, J., \& Hampton, K. (2001). Does the Internet increase, decrease, or supplement social capital?: Social networks, participation, and community commitment. American Behavioral Scientist, 45(3), 436-455.
Wilson, S. M., \& Peterson, L. C. (2002). The anthropology of online communities. Annual review of Anthropology, 31(1), 449-467.

Woodly, D. (2007). New competencies in democratic communication? Blogs, agenda setting and political participation. Public Choice, 134(1-2), 109-123.

Woolcock, M. (1998). Social capital and economic development: Toward a theoretical synthesis and policy framework. Theory and Society, 27(2), 151-208.

Zhang, W., Johnson, T. J., Seltzer, T., \& Bichard, S. L. (2009). The revolution will be networked: The influence of social networking sites on political attitudes and behavior. Social Science Computer Review, 28(1), 75-92. 